\section{The Mutability of Schizophrenia: From Hafner's Epidemiology to Hafner's Psychopathology}

\author{
Paul Brown \\ The Pierre Janet Centre, Australia
}

Corresponding author: Paul Brown

pierrejanetcentre@gmail.com

\section{Abstract}

This article examines the psychopathological mutability of schizophrenia and schizophreniform psychosis. It pursues this objective through the lens of the epidemiological investigations of schizophrenia of Heinz Hafner in Mannheim, Baden-Wurttemberg, over the half-century between 1965, and the present day. It suggests that variations in the incidence of schizophrenia, in post-war Germany, can be accounted for partly by social pressures, and partly by liberal diagnosticcum-epidemiological, professional practice. Core schizophrenia in post-war Germany, was accompanied by a wide range of schizophreniform psychoses, usually with affective features, better prognosis, and most importantly, probable environmental reactivity against a backdrop of genetic and epigenetic stresssensitivity. Comorbidity with alcohol and drug abuse was the rule. Hafner's findings are emblematic of those in both the Old World and the New, which demonstrate the mutability of schizophrenia in the modern era.
Received: September, 22 2015; Accepted: November 24, 2015, Published: December 07, 2015

\section{Introduction}

Beer [1], addressing the sociocultural and professional context of diagnosis of psychosis, wrote, "Throughout its 150 year history, the concept of psychosis has not been static, but has reflected the intellectual and social contexts in which it has been employed." He drew attention to "the different social milieux of patients being treated by psychiatrists such as Kraepelin ... led to different emphases regarding the aetiology of the psychoses." It also led to different emphases regarding their psychosocio-pathophysiology, and most prominently to different emphases regarding their diagnostic phenotypes and their classification. This study examines the interpenetration of these exogenous, professional and sociocultural factors in schizophrenia and its close diagnostic congeners, via the epidemiological lens of Heinz Hafner and his sociocultural and professional milieu. Hafner sought to steer schizophrenia along a middle path between nature and nurture. His total oeuvre demonstrates the evolution of schizophreniform psychopathology in the city where he worked: Mannheim, Germany.

\section{Torrey and Yolken}

The epidemiology of schizophrenia in Germany, in the twentieth century was accessed via a Torrey and Yolken [2] investigation of the Nazi attempt to eradicate schizophrenia. It estimated that between 1939 and 1945, 132,000 subjects suffering from schizophrenia were sterilized, and 100,000-137,500 with schizophrenia was killed. After the war, the prevalence of schizophrenia was, not surprisingly, low. In 1965, Hafner [3] conducted an ecological study of the incidence of treated mental disorders in Mannheim. The size of the index population, 330,000 , anticipated that of the local case register (covering the catchment area of the community mental health service), which was commenced in 1973. It was some 300,000 [4]. The incidence of schizophrenia was 53.6 per 100,000, two-to-three times higher than most comparable international studies at that time.

Torrey and Yolken analysed this high incidence. They first noted that the elimination of schizophrenia by the Nazis would have had no impact on its incidence, because most subjects do not have a family history of the illness, and they do not reproduce. Torrey and Yolken considered four further explanations for the high incidence. Three were discounted. The fourth, social conditions and environmental factors was considered "unknown."

Torrey and Yolken's first hypothesis, that Mannheim might have been less affected by psychiatric genocide was disproved by the existence nearby of centres for euthanasia: Grafeneck and 
later, Hadamar asylum. Secondly, Torrey and Yolken considered the possibly of inflation in the incidence of schizophrenia by non-German immigrants. They cited, as evidence against the hypothesis, the fact that Mannheim's rate of absorption of immigrants was significantly lower than those of the German population. But, a lower rate of immigration would not, necessarily, have affected the incidence of psychosis in immigrants at that locale. The immigration factor and its socioeconomic context therefore remained an open question.

The third explanation, "much broader diagnostic criteria were being used to diagnose schizophrenia in Germany after the war compared with before the war," was discounted by Torrey and Yolken, but is favoured by the present author. Torrey and Yolken hypothesised that with broader diagnostic criteria for schizophrenia, one would expect to find high rates in prevalence as well as in incidence studies. But, measurement of prevalence was in established cases. These had been diagnosed and then possibly coached by their carers, both professional and nonprofessional. By way of contrast, incidence was diagnosed by the team, Hafner's team. This warranted deeper study.

Might stress have been enough to account for the increased incidence of psychosis? In my view: partly so. Hafner examined alcohol and drug abuse and concluded that these were not a significant aetiological factor. The findings will be reported. Two, further exogenous factors stand out. In addition to Torrey and Yerken's 'unknown,' social conditions and environmental factors, professional psychiatric dispositions must be considered. These would not only be reflected in the findings for schizophrenia. They would also be reflected in the occurrence of a wide range of schizophreniform psychoses, identified or not, in which an aetiological, stress factor would be more or less prominent. First, social conditions and environmental factors are considered.

\section{Mannheim and Psychosocio- Pathogenic Stress}

From the second-half of the nineteenth century, Mannheim in Baden-Wurttemberg was a major industrial centre. It was half destroyed by the Allies in bombing raids, during World War II [5]. By the 1960s Mannheim was well on the way to reconstruction. There were new residential areas, but these were overshadowed by prestige projects: establishment of the University of Mannheim, the State Museum for Technology and Work, and the planetarium; building of the Stadthaus, the Market ground, the Carl-Benz stadium, the telecommunications and Victoria towers, the Fahrlach tunnel and a second bridge across the Rhine; and, the rebuilding of Mannheim Palace National Theatre, and the landmark water tower. Following World War II Mannheim housed a major American military garrison. In short, Mannheim was symbolic of the military-industrial juggernaut called modern civilisation. If ever there was a place to examine the vicissitudes of occidental, modern urban life, and their impact on mental health, Mannheim might well be it.

The Whig history of post-war West Germany centres on what was called 'the economic miracle.' (Wirtschaftswunder) This consisted in the reconstruction of the German economy. It led to low inflation and rapid industrial growth. The 'miracle' was achieved with the aid of Americans on the ground in the Old World, and the backing of the Marshall Plan from the New [6]. Germany became one of the strongest world economies. But it did not favour everyone equally.

The seeds of discontent were sown early. In 1919, during the Weimar Republic, Ludwig Mayer [7] published a study on mentally justified wanderlust. He contrasted this with homelessness, which he saw as a mental illness. Modern studies demonstrate that homelessness is both the cause and consequence of mental illness. A recent Mannheim investigation found that $79.3 \%$ of a study sample of individuals "immediately threatened by eviction" suffered from an acute mental disorder requiring treatment. These were stress-related disorder centering on alcohol dependence, and personality and mood disorders. Schizophrenia was well represented [8].

Not everyone regarded wanderlust as a healthy pursuit. For many it was a social pathology, termed vagabondage, one of several social pathologies [9]. Germany had always been, and remained a highly stratified society. This also applied in regard to access to health care [10]. The post-war, economic miracle did not relieve the plight of low-wage workers. Industry faltered, and it lost many industrial jobs. The underclass of the poor was inflated by old age pensioners, widows, [11, 12] children, [13] immigrants [14] and comparably disadvantaged groups. The middle and upper classes were inflated by nouveaux riches, leading to the contemporary problem of the ever-widening income gap. What were the symbols of poverty? Yellow envelopes were overdue payment notices [15]. Letters bearing a heraldic eagle were from the state. Coloured logos usually meant bills from telephone companies. Poverty in Mannheim, inflated by the immigrant component of the underclass was associated with rampant crime. Increasingly, it was drug-related crime. Here is a telling quote from a Mannheim blog, "It is always difficult to come here ... (there is) high drugcrime ... police patrols rotate day and night especially in the inner city ... large parts of the City are under camera surveillance for years! Friends of mine ... live ... approximately $20 \mathrm{~km}$ from Mannheim (in a) remote small town (about 10,000 inhabitants), where the trade of illegal drugs 'blossoms.' Police are there (for all) to see ... (once it was a) small country town idyll ... there, probably hardly anyone was "bad."'

Mental illness in Mannheim occurred against this backdrop of poverty and homelessness. It increasingly included drug and alcohol abuse. In neighbouring Bavaria, substance abuse even permeated the old age homes [16, 17]. Epidemic alcoholism extended to the homeless in Mannheim [18]. In his ecological study of psychiatric disorder in Mannheim, Maylath [19] wrote, "There was a marked increase in the concentration index for schizophrenia in the inner zone, as well as for neuroses and personality disorders between 1974 and 1980 as compared with 1965. There were strong concentrations in the inner zone during both periods of study for the diagnosis of alcoholism and drug addiction."

To be sure, homelessness, occupational stresses, and concomitant poverty, would have been concealed beneath the mask of modern 
material and recreational diversion. But the deeper stresses, including those based not only in personal memory, but also in historical memory of Nazi Germany were well represented. Mannheim was the birthplace of Albert Speer, architect, and from 1942, Hitler's Minister of Armaments and War Production. They were not only memories of compliance with Nazism. Mannheim, with its 'Mannheim Group,' was also a centre of Nazi resistance [20]. Beneath the mask of de-Nazification there remained conservative and fascistic currents; beneath the mask of reconstruction, there remained poverty and homelessness. Mannheim was not psychologically immune to these problems and their attendant pathologies.

Germany's economic miracle was, from the outset, facilitated by guest-workers from the east. By the 1970s, they contributed $13 \%$ of the population of Mannheim [21]. Baden-Wurttemberg was second only to North Rhine-Westphalia in hosting guest-workers. Economic migrants, mostly from Turkey, were required, not only to boost production, but to relieve the pressure on the local, working-class population. Those pressures must have resulted in psychological casualties. In some, it could be hypothesised, that took the form of psychiatric illness, including psychosis. Torrey and Yolken considered social conditions 'unknown.' They did not reference them. Nor did Hafner reference the contemporaneous sociological, socio - political or social historical literature. Binder and Simoes [22] wrote, towards the end of the 1970s, in regard to putative increase in incidence of mental illness in migrant workers, "Results concerning incidence and prevalence of psychic disease in migrant workers are contradictory and partly for methodological reasons of questionable quality." That statement might equally apply to the reverse: the putative lower incidence and prevalence of mental illness in this population. Paranoid psychoses appear to have been well represented. Guest-workers and their families were associated with as many socio-economic [23] and psychiatric problems in the Germanophone world in that generation [24-26] and in the generation that followed it, [27, 28] as they might have relieved. Hafner, [29] himself, early noted these epidemiological trends.

\section{Hafner at Mannheim}

The diagnostic practice of the German, epidemiological investigator, Heinz Hafner, is now examined. He is the doyenne of European epidemiologists, trained in philosophy (Scheler's phenomenology, and Heidegger's Dasein), and with a lifelong of psychiatric service with a social conscience. He sought psychiatric reform in post-war Germany. Sociotherapy was at the forefront of his therapeutic armamentarium [30, 31]. In 1965, the time when he was engaged in the Manheim epidemiological study, Hafner published a chronicle of the plight of the mentally ill in Germany. His acknowledgment of the environmental factor in the causation of mental illness was also manifested in a sympathetic, contemporaneous study of concentration camp survivors claiming compensation payment.

Torrey's guestimate of Hafner's putative, Kraepelinian diagnostic orientation, albeit under the rubric of ICD 8 and ICD 9, begs more questions than it answers. Kraepelin was more concerned with the course, prognosis and diagnostic differentiation of the psychoses. Angst [32] wrote, "In his later years (Kraepelin) was close to revising his own celebrated dichotomy between manicdepressive insanity and dementia praecox in order to take account of a large group of intermediate psychoses, which today are called schizo-affective." Kraepelin also had a strong interest in social and cultural dimensions of mental illness.

Phenotypic specification of schizophrenia only peaked with the work of the anti-Nazi Heidelberg psychiatrist, Kurt Schneider, and his Front Rank Symptoms [33]. These determined the Research Diagnostic Criteria for schizophrenia, [34] and the operational criteria of that diagnosis in DSM-III. They have had their day, at least as the defining feature of 'schizophrenia.' It is by no means clear that they were to the fore in Hafner's diagnostic practice.

\section{Hafner and Schizophrenia}

Hafner's early studies of schizophrenia, like many during the preoperationalization era, were marked by a degree of vagueness. Subsequent studies suggest that Hafner's diagnostic approach was always more inclusive, covering schizophreniform and schizophrenia spectrum disorder. Negative rather than positive symptoms were pathognomonic, and "Some negative symptoms also seemed to be linked to a depressive state" [35]. Hafner [36] concluded that nuclear schizophrenia is at "the lower end" of a broadly extending, spectral, genetic dimension of morbidity. High vulnerability is associated with more specific, endogenously determined psychopathology. Spectral forms, ranging across the range of schizophreniform conditions, are increasingly associated with increasing influence of emotional features, notably depression, and personality and environmental factors.

\section{Schizophrenia and Depression}

Hafner's view that depression is constitutive to schizophrenia likely widened his diagnosis. It also linked schizophrenia with stress, since that condition is far less controversially associated, aetiologically, with stress. A meta-analysis of five studies of the genetic epidemiology of depression revealed a genetic contribution of $37 \%$ for unipolar depression [37]. Much of this contribution appears to be epigenetically mediated [38]. Common environmental influences had very small effects, but individual environmental factors showed a contribution of $63 \%$. Most of the research effort in contemporary psychiatry has been directed at validating the link between early life stress and adult depression. This restricted view of the place of stress in depression is most likely based in a historical bias. It originated at the time when psychiatrists were trained in, and influenced by psychoanalytically informed, developmental dynamics. Further, the current focus in stress- psychiatry is mostly on PTSD. It is only a matter of time before ongoing stress in depression, and in fact in all psychiatric disorder, comes within mainstream psychiatric purview.

The significance of Hafner's inclusion of depression was even more fundamental. It linked Hafner's, and his ABC school's conceptualisation of schizophrenia with those of unitary psychosis in the nineteenth century oeuvres of Griesinger and Guislain. For the latter, depressive 'phrénalgie initiale' was regarded as the initial stage of all psychiatric illness [39]. This conceptualisation 
reached a far wider audience in Griesinger's [40] notion of the unitary psychosis. In it, he described an initial transition from normal emotions to mental depression, thence via hypochondria to melancholia and finally mania. That mania was subsequently dichotomised between dementia praecox (later schizophrenia) and manic depression by Kraepelin.

In an epidemiological study published in 2007, [41] which followed two decades of investigation of gender and schizophrenia under the rubric of the binational, Germany- Denmark, schizophrenia epidemiology project, the $A B C$, Hafner played down the female gender factor. Instead he concluded, "Illness onset in depression and schizophrenia is marked by identical symptoms, mostly depressive in type. Throughout the course of schizophrenia, depression is the most frequent symptom. Psychosis risk increases when depressive and anxiety symptoms increase and decreases when these symptoms decrease," and, "Depressive symptoms are particularly frequent during a psychotic episode at a rate of approximately 50\%" [42]. The depressive symptoms were most apparent in the prodromal [43] and post-psychotic phases of schizophrenia, overshadowed between-times by the powerful symptoms of psychosis [44]. He concluded, "Schizophrenic psychosis and severe affective disorder, rather than representing discrete illnesses, probably mark different stages in the manifestation of psychopathology" [45]. Hafner and his group were drawn to dimensional views of psychosis, and to a hierarchical view, "not unknown to the later Kraepelin," [46] and reminiscent of Fould's [47, 48] 'hierarchy of classes' of mental illness. Both conceptions facilitated the accommodation of the combined schizophreniform and affective features of the psychosis. Citing "not very specific" results Hafner [49] opted for a neuropathological basis for schizophrenia. Disordered brain development was, however, "very likely not specific to schizophrenia" [50]. Rather, neuropathology consisted in a "recurrent vulnerability to crisis and not of a stable residual state of disordered brain development or of a progressive neurodegenerative process" [51]. Hafner was apparently favouring nurture over nature, epigenesis over genesis. Hafner, [52] however, in accord with the social drift theory, assigned nurture a critical role in shaping pre-established illness. He did not consider a more fundamental causal role.

\section{Schizophrenia and Schizophreniform Psychosis}

The descriptive validity of schizophrenia is not high. Those who assert that it is rely primarily on factors such as age and gender [53]. Negative symptoms appear to be at least as important as positive symptoms, if not more so. However, they can be very difficult to differentiate from the symptoms of depression, and of other schizophreniform disorders. Hafner sought to accommodate these negative symptoms with depressive symptoms. Numerous attempts have been made to validate schizoaffective disorder alongside paranoid disorder, atypical psychosis, reactive psychosis, cycloid psychosis, psychogenic psychosis, and hysterical psychosis. Hafner [54] located such conditions on a spectrum from schizophrenia to schizothymic personality. There is, he avers, a continuously distributed latent vulnerability to schizophrenia which increasingly disposes to a pathognomonic "reaction pattern of the schizophrenia syndrome."

Hafner's views on schizophrenia, its reactivity and related, wide, diagnostic spectra must have been influenced by the work of his Germanophone colleagues: Klaus Conrad in Munich; [55] Karl Kleist at Frankfurt; [56] and, Karl Leonhard in East Berlin [57, 58]. This was quite apart from the influence of the relatively local Scandinavian psychiatrists: G Langfeldt; [59] O Odegard; [60] and, A Wimmer [61]. However, no dialogue on the schizophrenia spectrum is recorded by him with these Old World investigators, or those in the New. Nor did he relate to the investigation of schizoaffective disorder, per se. These statements are not intended as a criticism. Evidently, Hafner saw himself as an epidemiologist, and not as a psychopathologist. However, the importance of his epidemiological work and its implications for psychopathology behove further such analysis of his oeuvre, and further empirical exploration of his psychopathological findings.

\section{Schizophrenia and Substance Abuse}

Hafner's team examined the causal relationship between schizophrenia and substance abuse in their $A B C$ Schizophrenia Study [62-64]. A first-episode sample of 232 schizophrenic patients (catchment area population of $1,500,000$ ) was identified using The Interview for the Retrospective Assessment of the Onset of Schizophrenia and Other Psychoses (IRAOS). Alcohol abuse prior to first admission was found in $24 \%$, drug abuse in $14 \%$. These rates were twice those in the general population. Male sex and early symptom onset were major risk factors.

Alcohol abuse usually started during the prodromal phase. Drug-abusers were younger than alcohol-abusers. Drug abuse emerged before the first symptom in one third, simultaneously with it in another third, and during the prodromal phase in the last third of patients. The hypothesis that substance abuse causes schizophrenia was not supported, nor was a specific psychotic disorder in comorbid cases. A small proportion of schizophrenias might have been precipitated by substance abuse, mainly cannabis. Five-year outcome was poorer for those with early substance abuse.

Hafner's team noted that past studies were mostly conducted with chronic, mixed stages of schizophrenia [65]. Their study identified three approximately equal groups: group 1 had been abusing cannabis for several years before the first signs of schizophrenia emerged; group 2 experienced the onset of both disorders within the same month; and, group 3 had started to abuse cannabis, after the onset of symptoms of schizophrenia. They interpreted these findings according to the vulnerabilitystress-coping model of schizophrenia. In group 1, chronic cannabis use reduced the vulnerability threshold and/or coping resources. In group 2, cannabis misuse was the (dopaminergic) stress factor precipitating the onset of psychosis. In group 3, cannabis was used for self-medication against (or for coping with) symptoms of schizophrenia, particularly negative and depressive symptoms. They probably learn to counterbalance a hypo-dopaminergic prefrontal state by the dopaminergic effects of cannabis. 


\section{Conclusion}

Three apparently related diagnostic dimensions have shadowed schizophrenia, and diagnostic practises in relation to it, since its delineation by Kraepelin and Bleuler: affectivity, recoverability and reactivity. These three dimensions are constitutive to Hafner's conceptualization of schizophrenia. However, his notion of reactivity was not expanded to take into account the true breadth and depth of the stressful, socio-cultural, Mannheim historical context. Rather he adhered to the drift hypothesis, and restricted the role of society to 'sequel' rather than 'precursor' [66]. The Mannheim ABC study demonstrated that social disability correlated highly with negative rather than positive symptoms of schizophrenia. Disability was present in $57 \%$ of patients prior to the onset of the first psychotic symptom. It generally began up to four years before first hospitalisation, and one to three years before first psychotic symptom. The present analysis is as much concerned with what came before first hospitalisation, and before first psychosis. Quite apart from the proximal, socio -cultural dimension of ontogeny, it is concerned with the impact on psychopathology of the socio-cultural dimension of phylogeny, and its impact on ontogeny.

The historical process, when observed alone through the reducing lens of the human and social sciences, does not do justice to its psychopathogenic power. The present diagnostic approach restores phylogeny to ontogeny, social and cultural history to social science, and hence to psychopathology in psychiatry. It encourages the identification of stresses both synchronically and diachronically, and thereby enables their qualitative and quantitative empirical valuation. This equally involves their relationship to ontogenetic, stress-sensitivity, not only during early development, but also throughout the life-cycle, mediated by genetic and epigenetic mechanisms.
The current diagnostic zeitgeist, the biomedical model has virtually abandoned reactivity. Zmitek [67] recently observed, "When looking back in the history of psychiatry, the concept of reactivity had very variable impact on aetiological considerations. If classification of mental disorders is taken as a proxy, it seems that this impact is presently at the lowest that it has been in the last hundred years." He concluded "Reintroduction of a certain degree of the reactivity concept into the classification seems to be required." The present approach seeks to 'resurrect' it.

In post-war Mannheim as in pre-war, the level of stress in the community must have been extraordinarily high. It centred on poverty, homelessness, and work-stress, complicated by crime and substance abuse. The latter, however, does not appear to have played a major causal role. This was against a historical backdrop of social stratification, immigration, state control, and fascism in the form of Nazism. The German publisher, and Holocaust denier, Ernst Zundel, was detained in the US in 2003, deported to Canada, and thence to Germany, where he was tried in the state court of Mannheim. He served the maximum term of five years in prison [68]. A neo-Nazi, Christian Hehl, was recently voted into Mannheim city council [69]. Extreme stresses especially targeted the young and the old, and those in the lower socio - economic classes. It would have been reflected in the high incidence, not only of schizophrenia and schizoaffective psychoses, as identified by Hafner, but also of the entire range of stress disorders. It is the present author's contention that variations in the overall rate of mental illness in a given society reflect variations in the nature and intensity of stress in that society. Increase in stress is reflected in increase in stressrelated disorder, notably anxiety and depression, personality disorder, dissociative disorder, and comorbid substance abuse, and vice versa. In regard to schizophrenia, it would also include the panoply of schizophreniform psychoses in which reactivity predominated over endogeneity. 


\section{References}

1 Beer MD (1995) The importance of the social and intellectual contexts in a discussion of the history of the concept of psychosis. Psychol Med 25: 317-321.

2 Torrey EF, Yolken RH (2010) Psychiatric genocide: Nazi attempts to eradicate schizophrenia. Schizophr Bull 36: 26-32.

3 Hafner H, Klug J (1982) The impact of an expanding community mental health service on patterns of bed usage: evaluation of a four-year period of implementation. Psychol Med 12: 177-190.

4 Hafner H, Reimann H (1970) Spatial distribution of mental disorders in Mannheim, 1965. In, EH Hare and JK Wing, editors, Psychiatric Epidemiology: Proceedings of the international symposium held at Aberdeen University, 22-5 July, 1969. New York, NY: Oxford University Press, 341-354.

5 Tessler R, Davidson E (1999) Germany: An Account of the American Occupation. Columbia, MO: University of Missouri Press.

6 Carlin W (1993) West German growth and institutions, 1945-90.

7 Mayer L (1919) Die Wandertrieb. Wurzburg: PhD dissertation.

8 Salize HJ, Dillmann-Lange C, Kentner-Figura B, Reinhard I (2006) Threatened homelessness and mental disorders. Prevalence and influencing factors in populations at risk. (Article in German) Nervenarzt 77: 1345-1354.

9 Spicker F (1976) The German wanderer, vagabond and Vagantenlyrik in the years 1910-1933. Berlin: Walter de Gruyter.

10 Helmert U, Mielck A, Shea S (1997) Poverty and health in West Germany. Soz Praventiv Med 42: 276-285.

11 Naegele G (1979) Requirements for security for widows according to their needs. Remarks on the discussion on dependents' allowance in West Germany. (Article in German) Z Gerontol 12: 294-305.

12 Standfest E (1979) Economic situation of widows in West Germany. (Article in German) Z Gerontol 12: 289-293.

13 Lampert T, Schenk L, Stolzenberg H (2002) Conceptualization and operationalization of social inequality in the Child and Adolescent Health Survey. Gesundheitswesen 64: S48-52.

14 Gezer O (2012) Bulgarian and Romanian immigrants overwhelm German system. Der Spiegel.

15 Rohrmann E (1987) Without work, without a dwelling. How to arm the nomads. (Book in German) Berlin: Edition Schindele.

16 Fichter M, Quadflieg N, Greifenhagen A, Koniarczyk M, Wolz J (1997) Alcoholism among homeless men in Munich, Germany. Eur Psychiatry 12: 64-74.

17 Fichter M, Quadflieg N (1999) Alcoholism in homeless men in the midnineties: results from the Bavarian Public Health Study on homelessness. Eur Arch Psychiatry Clin Neurosci 249: 34-44.

18 Salize HJ, Dillmann-Lange C, Stern G, Kentner-Figura B, Stamm K, et al. (2002) Alcoholism and somatic comorbidity among homeless people in Mannheim, Germany. Addiction 97: 1593-600.

19 Maylath E, Weyerer S, Hafner H (1989) Spatial concentration of the incidence of treated psychiatric disorders in Mannheim. Acta Psychiatr Scand 80: 650-6.

20 McDonough F (2001) Opposition and resistance in Nazi Germany. Cambridge, England Cambridge University Press.

21 Ellrich H (2007) Mannheim. Erfurt: Sutton.

22 Binder J, Simoes M (1978) Social psychiatry of migrant workers (Article in German). Fortschr Neurol Psychiatr Grenzgeb 46: 342-359.
23 Mueller C (2006) Integrating Turkish communities: a German dilemma 25: 419-441.

24 Friessem DH (1974) Psychiatric and psychosomatic diseases of foreign workers in the Federal Republic of Germany. A contribution to psychiatry of migration. (Article in German) Psychiatr Neurol Med Psychol (Leipz) 26: 78-90.

25 Riedesser R (1975) Mental disorders in foreign workers in the Federal Republic of Germany. Causes, problems and socio-political sequelae. (Article in German) Med Klin 70: 954-999.

26 Boker W (1977) Notes on the psychic morbidity of foreign laborers in the Federal Republic of Germany-review of findings and hypotheses. (Article in German) Offentl Gesundheitswes 39: 720-732.

27 Ayalan S, Fischer P, Naske R (1993) Behavioral problems in children of Turkish guest workers in Vienna. (Article in German) Z Kinder Jugendpsychiatr 21: 226-232.

28 Morawa E, Erim Y (2014) Acculturation and depressive symptoms among Turkish immigrants in Germany. Int. J. Environ. Res. Public Health 11: 9503-9521.

29 Hafner H, Moschel G, Ozek M (1977) Psychiatric disturbances in Turkish guest-workers in Germany. A prospective study of 200 immigrants. Article (in German) Nervenarzt 48: 268-275.

30 Hafner H (1966) Sociotherapy and rehabilitation of schizophrenic patients. (Article in German) Med Klin 61: 649-653.

31 Hafner H (1967) Experiences with sociotherapy of schizophrenics. (Article in German) Ned Tijdschr Geneeskd 111: 1735-1736.

32 Angst J, Gamma A (2008) Diagnosis and course of affective psychoses: was Kraepelin right? Eur Arch Psychiatry Clin Neurosci 258: 107-110.

33 Schneider K (1959) Clinical Psychopathology. New York: Grune and Stratton.

34 Spitzer RL, Robins E (1978) Research diagnostic criteria: rationale and reliability. Archives of General Psychiatry 35: 773-782.

35 Lutzhoft JH, Skadhede S, Fatkenheuer B, Hafner H, Loffler W, et al. (1995) Symptom assessment in case-notes and the clinical diagnosis of schizophrenia. Psychopathology 28: 131-139.

36 Hafner H (1989) Application of epidemiological research toward a model for the etiology of schizophrenia. Schizophr Res 2: 375-383.

37 Sullivan PF, Neale MC, Kendler KS (2000) Genetic epidemiology of major depression: review and meta-analysis. Am J Psychiatry 157: 1552-1562.

38 Menke A, Binder EB (2014) Epigenetic alterations in depression and antidepressant treatment. Dialogues Clin Neurosci 16: 395-404.

39 Van Renynghe de, Voxvrie G (1993) Reactualization of the concept of unitary psychosis introduced by Joseph Guislain. Acta Psychiatr Belgica 93: 203-219.

40 Griesinger J (1882) Mental pathology and therapeutics. Translated by CL Robertson and J Rutherford. New York: William Woods.

41 Hafner $\mathrm{H}$ (2007) Is the schizophrenia diagnosis still appropriate? (Article in German) Psychiatr Prax 34: 175-180.

42 An der Heiden W, Konnecke R, Maurer K, Ropeter D, Hafner H (2005) Depression in the long- term course of schizophrenia. Eur Arch Psychiatry Clin N eurosci 255: 174-184.

43 Hafner H, Maurer K, Trendler G, an der Heiden W, Schmidt M, et al. (2005) Schizophrenia and depression: challenging the paradigm of two separate 
diseases: a controlled study of schizophrenia, depression and healthy controls. Schizophr Res 77: 11-24.

44 Bustamante S, Maurer K, Loffler W, Hafner H (1994) Depression in the early course of schizophrenia. (Article in German) Fortschr Neurol Psychiatr 62 317-329.

45 Hafner H, Maurer K, An der Heiden W (2013) ABC schizophrenia study: an overview of results since. Soc Psychiatry Psychiatr Epidemiol 48: 1021-1031.

46 Hafner $\mathrm{H}$, an der Heiden W, Maurer K (2008) Evidence for separate diseases? Stages of one disease or different combinations of symptom dimensions? Eur Arch Psychiatry Clin Neurosci 258: 85-96.

47 Foulds GA, Bedford A (1975) Hierarchy of classes of personal illness. Psycho Med 5: 181-192.

48 Foulds GA, Bedford A, Csapo KG (1975) Class change in the personal illness hierarchy. Br J Psychiatr 127: 316-319.

49 Hafner H (2004) Schizophrenia still Kraepelin's dementia praecox? Epidemiol Psichiatr Soc 13: 99-112.

50 Hafner H (1995) Epidemiology of schizophrenia. The disease model of schizophrenia in the light of current epidemiological knowledge. Eur Psychiatry 10: 217-227.

51 Hafner H, Maurer K, An der Heiden W (2013) Schizophrenia: a disorder in its own right? Results from 25 years of the $A B C$ study. (Article in German) Nervenarzt 84: 1093-4, 1096-103.

52 Loffler W, Hafner H (1999) Ecological pattern of first admitted schizophrenics in two German cities over 25 years. Soc Sci Med 49: 93-108.

53 Jager M, Bottlender R, Strauss A, Moller HJ (2003) On the descriptive validity of ICD-10 schizophrenia: empirical analyses in the spectrum of non-affective functional psychoses. Psychopathology 36: 152-159.

54 Hafner H (1988) What is schizophrenia? Changing perspectives in epidemiology. Eur Arch Psychiatry Neurol Sci 238: 63-72.

55 Mishara AL (2010) Klaus Conrad (1905-1961): delusional mood, psychosis, and beginning schizophrenia. Schizophr Bull 36: 9-13.
56 Salvatore P, Bhuvaneswar C, Ebert D, Maggini C, Baldessarini RJ (2008) Cycloid psychoses revisited: case reports, literature review, and commentary. Harv Rev Psychiatry 16: 167-180.

57 Von Trostorff S, Leonhard K (1990) Catamnesis of endogenous psychoses according to the differential diagnostic method of Karl Leonhard. Psychopathology 23: 259-262.

58 Perris C (1990) The importance of Karl Leonhard's classification of endogenous psychoses. Psychopathology 23: 282-290.

59 Bergem AL, Dahl AA, Guldberg C, Hansen H (1990) Langfeldt's schizophreniform psychoses fifty years later. Br J Psychiatry 157: 351-354.

60 Dahl AA, Cloninger CR, Guze SB, Retterstol N (1992) Convergence of American and Scandinavian diagnoses of functional psychoses. Compr Psychiatry 33: 13-16.

61 Bergem AL, Dahl AA, Guldberg C, Hansen H, Castagnini AC (2010) Wimmer's concept of psychogenic psychosis revisited. Hist Psychiatry 21: 54-66.

62 Hambrecht M, Hafner $H$ (1996) Substance abuse and the onset of schizophrenia. Biol Psychiatry 40: 1155-1163.

63 Buhler B, Hambrecht M, Loffler W, An der Heiden W, Hafner H (2002) Precipitation and determination of the onset and course of schizophrenia by substance abuse: a retrospective and prospective study of 232 populationbased first illness episodes. Schizophr Res 54: 243-251.

64 Hambrecht M, Hafner H (1996) Do alcohol or drug abuses induce schizophrenia? Article in German. Nervenarzt 67: 36-45.

65 Hambrecht M, Hafner H (2000) Cannabis, vulnerability, and the onset of schizophrenia: an epidemiological perspective. Aust NZJ Psychiatry 34: 468-475.

66 Maurer K, Bentz C, Loffler W, Hafner H (1996) Psychiatric handicap: precursor or social sequelae of schizophrenia? (article in German). Gesundheitswesen 58: 79-85.

67 Zmitek A (2009) Hommage to reactive psychosis. Psychiatr Danub 21: 26-28.

68 The Zundel Affair, Shofar FTP Archives, nizkor.net

69 Spiegel Staff (2014) Germany's New Right: the unholy alliance of Neo-Nazis and football hooligans. Spiegel On-line International. 